\title{
Conceitos de administração de empresas na gestão de periódicos científicos
}

\author{
SBRUZZI, Dyanara Lays Rohte ${ }^{*}$ \\ ${ }^{1}$ União Pioneira de Integração Social - Brasil \\ ORCID ID: https://orcid.org/0000-0002-4914-3438*
}

\begin{abstract}
Resumo
Os periódicos científicos (PC) possuem uma estrutura que necessita de controles bem estabelecidos, que vão desde a submissão dos manuscritos até a pós-publicação, por isso, podem e devem se utilizar de técnicas de gestão. O objetivo deste trabalho é relacionar os conceitos da administração de empresas com as definições da gestão de PC, servindo como guia para novos colaboradores da área editorial. Trata-se de um estudo exploratório descritivo que visa contribuir com informações úteis aos gestores. A separação por departamentos possibilitou a comparação das atividades e as definições correlacionadas com os PC demonstraram que os gestores, mesmo sem experiência anterior na edição de PC, podem buscar soluções alternativas. Conclui-se, portanto, que a assimilação de conceitos de administração de empresas com as definições da gestão de PC serve como guia para novos colaboradores da área editorial.
\end{abstract}

Palavras-chave: Administração de empresas. Gestão. Periódico Científico.

Business administration concepts in the management of science journals

\begin{abstract}
Science journals (SJ) have a structure that requires well-established controls that range from manuscript submission to post-publication, and therefore can and should use management techniques. The objective of this work is to relate the concepts of business administration with the definitions of SJ management, serving as a guide for new collaborators in the editorial area. This is an exploratory, descriptive study that aims to contribute useful information to managers. Departmental separation enabled the comparison of activities and the use of definitions correlated to the SJ demonstrated that managers, even without previous experience in SJ editing, can seek alternative solutions. It is concluded, therefore, that the assimilation of business administration concepts with the definitions of SJ management serves as a guide for new collaborators in the editorial area.
\end{abstract}

Keywords: Business administration. Management. Science Journal.

\section{Conceptos de administración de empresas en la gestión de revistas científicas}

\section{Resumen}

Los periódicos científicos (PC) tienen una estructura que necesita controles bien establecidos que van desde el envío de manuscritos hasta el post-publicación, por tanto, pueden y deben utilizar técnicas de gestión. El objetivo de este trabajo es relacionar los conceptos de administración de empresas con las definiciones de gestión de PC sirviendo de guía para nuevos colaboradores en el área editorial. Se trata de un estudio exploratorio y descriptivo que tiene como objetivo aportar información útil a los directivos. La separación por departamentos permitió comparar actividades y las definiciones correlacionadas con el PC demostraron que los gerentes, incluso sin experiencia previa en edición de PC, pueden buscar soluciones alternativas. Se concluye, por tanto, que la asimilación de los conceptos de administración de empresas con las definiciones de gestión de PC sirve de guía para los nuevos colaboradores en el área editorial.

Palabras clave: Administración de Empresas. Gestión. Periódico Científico. 


\section{Introdução}

Os periódicos científicos (PC) promovem o progresso da ciência. Segundo a American Psychological Association: "Os PC representam o meio mais vital de divulgação dos resultados das pesquisas e geralmente são especializados em diferentes disciplinas ou subdisciplinas acadêmicas" (APA, 2017, tradução livre). Ainda complementa que "os artigos de periódicos podem incluir pesquisas originais, reanálises de pesquisas, revisões de literatura em uma área específica, propostas de teorias novas, mas não testadas, ou artigos de opinião" (APA, 2017, tradução livre). No ano de 2018 foram publicados mais de 3.900.000 artigos, sendo a área de Ciências Médicas e da Saúde a categoria com maior contribuição, com cerca de 1.073.900 artigos. (DIMENSIONS, 2020).

O mercado de publicações científicas envolve instituições privadas e públicas, e vem se tornando uma política de estado necessária nos governos que buscam ascensão econômica. $\mathrm{O}$ Relatório de Ciência da Organização das Nações Unidas para a Educação, a Ciência e a Cultura (UNESCO) de 2015 revela que "muitos países estão agora incorporando a ciência, a tecnologia e a inovação em suas agendas de desenvolvimento nacional para tornar suas economias menos dependentes de matérias-primas e mais embasadas no conhecimento" (HYUDA; CHAIMOVICH, 2015, p. 60). Em 2018, por exemplo, o Produto Interno Bruto mundial foi de US\$ 87,751 trilhões, e as despesas com pesquisa e desenvolvimento representaram $2,274 \%$, o que correspondeu a uma participação de US\$ 1,995 trilhões (THE WORLD BANK, 2020).

Os PC possuem uma estrutura que necessita de controles bem estabelecidos, que vão desde a submissão dos manuscritos até a pós-publicação, e, por esse motivo, podem e devem se utilizar de técnicas de gestão. Diante disso, o objetivo deste trabalho é relacionar os conceitos da administração de empresas com as definições da gestão de PC, servindo como guia para novos colaboradores da área editorial.

\section{Metodologia}

Trata-se de um estudo exploratório descritivo que visa contribuir com informações para a gestão de PC. Delimitou-se a estrutura de uma empresa em quatro departamentos, correlacionando as atividades desenvolvidas nas empresas e nos PC. 


\section{Resultados e Discussão}

Os PC desenvolvem um ritual de trabalho específico com nomenclaturas desconhecidas para o público em geral. Um estudo de casos que analisou a gestão de PC em revistas da área de administração demonstra exatamente essa dificuldade:

Nas entrevistas com os editores, identificou-se que nenhum deles apresentava experiência anterior na edição de um periódico científico quando assumiu a editoria do periódico em questão [...]. Os editores entrevistados acabaram aprendendo na prática e com o auxílio de ex-editores que atuaram nas revistas. (SANDESGUIMARÃES; DINIZ, 2014, p. 459).

Para diminuir a carência de informações a respeito do como gerir um periódico científico, é possível usufruir das definições do meio empresarial, aproveitando técnicas e ferramentas que já existem no mercado e que possam guiar os novos colaboradores nas suas funções (Quadro 1).

Quadro 1. Relação entre empresa e periódico científico

\begin{tabular}{|c|c|c|}
\hline DEPARTAMENTO & EMPRESA & PERIÓDICO CIENTíFICO \\
\hline \multirow{2}{*}{ ADMINISTRATIVO } & Recursos humanos & Conselho editorial \\
\cline { 2 - 3 } & Governança coorporativa & Política editorial \\
\hline \multirow{2}{*}{ COMERCIAL } & Clientes & Autores \\
\cline { 2 - 3 } & $\begin{array}{c}\text { Marketing, publicidade e } \\
\text { propaganda }\end{array}$ & Divulgação científica e análise das métricas \\
\hline \multirow{2}{*}{ FINANCEIRO } & Receita & Taxas e financiamentos \\
\cline { 2 - 3 } & Custo & Gestão científica e administrativa \\
\hline \multirow{2}{*}{ OPERACIONAL } & Ferramenta e metodologia & Sistema de submissão e processo de avaliação \\
\cline { 2 - 3 } & Prestação do serviço & Procedimento de publicação \\
\hline
\end{tabular}

Fonte: Elaboração da autora (2020).

\subsection{Departamento administrativo}

O departamento administrativo gerencia os recursos humanos de forma coordenada para o cumprimento da governança corporativa. Nos PC os recursos humanos são os membros do conselho editorial, e a governança corporativa é a política editorial:

É preciso que [...] a existência e a perenidade da publicação estejam explicitamente mencionadas. A existência de uma retaguarda institucional implica a existência do Comitê ou Conselho de Política Editorial. Trata-se de um grupo de quatro a nove pessoas representativas: (1) da ou das entidades que integram a retaguarda; (2) de órgãos de fomento; (3) de instituições de pesquisas em geral; (4) da ou das áreas 
profissionais que aplicam o conhecimento veiculado na revista; (5) outras que a retaguarda institucional julgar convenientes. (TRZESNIAK, 2009, p. 88).

\subsection{Departamento comercial}

Toda empresa possui uma atividade fim a que se despõe oferecer a seus clientes e faz a divulgação dos seus serviços ou produtos por meio do marketing, da publicidade e da propaganda. A publicação de artigos científicos é a atividade fim dos PC e os seus clientes são os autores. A imagem construída pelo marketing, pela publicidade e pela propaganda pode ser feita por meio da divulgação científica, e o seu melhoramento é respaldado na análise das métricas. Métricas alternativas, que produzem "indicadores alternativos de visibilidade e impacto da produção científica considerando, para isso, os acessos, compartilhamentos e citações feitas por blogs, pela mídia e redes sociais" (BARATA, s.d.), estão surgindo para acompanhar o crescimento das mídias sociais, e a visão sobre a divulgação científica está se reformulando:

Embora a divulgação científica não seja, muitas vezes, vista como parte das atividades da comunidade acadêmica ou mesmo de periódicos científicos, cujo papel sempre foi comunicar a ciência para pares, se coloca, crescentemente, como atividade necessária, relevante e, até, obrigatória para que se estabeleça uma ponte definitiva entre ciência e sociedade (BARATA, s. d.).

\subsection{Departamento financeiro}

Fontes de financiamento e as receitas oriundas da atividade fim das empresas dão subsídio para que elas possam arcar com os seus custos. Nos PC, são as instituições mantenedoras ou as instituições que investem em pesquisa que liberam os financiamentos e as receitas advêm das taxas "de processamento de artigo (article processing charge, APC) [...]. Esta taxa pode ser paga pelo autor, instituição do autor ou seu financiador de pesquisa" (SPINAK, 2019). Já os custos envolvidos no processo de produção dos artigos compreendem a gestão científica (gerenciamento do processo de certificação de conteúdo do periódico) e a gestão administrativa (gerenciamento do processo de publicação) (SANDES-GUIMARÃES; DINIZ, 2014, p. 453).

\subsection{Departamento operacional}

O departamento operacional é o responsável por conduzir os PC. O sistema de submissão de artigos é a ferramenta que os PC operam, e o processo de avaliação escolhido é a metodologia, a configuração do sistema. A gestão sustentável do procedimento de publicação precisa considerar:

[...] eficácia (atingir os objetivos declarados), eficiência (minimizar os recursos utilizados para atingir o objetivo estabelecido) e a durabilidade (possibilidade de operar ao longo do tempo), o que muitas vezes implica a introdução de inovações 
soluções para lidar com um contexto em mudança. (DUBINI; GIGLIA, 2017, p. 242, tradução livre).

\section{Considerações finais}

Conforme apresentado, a separação por departamentos possibilitou a comparação das atividades empresariais com as definições dos PC. Diante disso, seria interessante um estudo de casos com uma amostra variada para verificar como a multidisciplinaridade pode contribuir com novas perspectivas na administração dos PC.

Conclui-se, portanto, que a assimilação de conceitos de administração de empresas com as definições da gestão de PC serve como guia para novos colaboradores da área editorial.

\section{Referências}

AMERICAN Psychological Association. What Are Scientific Journals? 2017. Disponível em: https://www.apa.org/advocacy/research/defending-research/scientific-journals. Acesso em: 29 ago. 2020.

BARATA, Germana. A importância da divulgação científica como prática acadêmica. Associação Brasileira de Editores Científicos. ABEC Brasil. Disponível em: https://www.abecbrasil.org.br/index.asp?include=noticias_newsletter\&id=5\&Parte=2. Acesso em: 29 ago. 2020.

DIGITAL Science \& Research Solutions, Inc. Dimensions. 2020. Disponível em: https://app.dimensions.ai/discover/publication?or_facet_publication_type=article\&or_facet_year= 2018. Acesso em: 29 ago. 2020.

DUBINI, Paola; GIGLIA, Elena. Economic sustainability during transition: the case of scholarly publishing. Proceedings of the International Conference on Electronic Publishing, p.239-261, 2009. Disponível em: https://elpub.architexturez.net/system/files/pdf/124_elpub2009.content_0.pdf. Acesso em: 14 set. 2020.

HYUDA, Renato de Luna Pedrosa; CHAIMOVICH, Hernan. Relatório de Ciência da UNESCO. Oxford: Baseline Arts Ltd, 2015. Disponível em: http://www.secti.pe.gov.br/wpcontent/uploads/2016/04/Unesco_relatorio.pdf. Acesso em: 29 ago. 2020.

SANDES-GUIMARÃES, Luisa Veras de; DINIZ, Eduardo H. Gestão de periódicos científicos: estudo de casos em revistas da área de Administração. Revista de Administração (São Paulo), v.49, n.3, p.449-461, 2014. Disponível em: https://www.scielo.br/pdf/rausp/v49n3/a02v49n3.pdf. Acesso em: 29 ago. 2020.

SPINAK, Ernesto. Periódicos que aumentaram o valor da APC receberam mais artigos. SciELO em Perspectiva, 2019. Disponível em: https://blog.scielo.org/blog/2019/05/22/periodicos-queaumentaram-o-valor-da-apc-receberam-mais-artigos/. Acesso em: 14 set. 2020. 
THE World Bank. Research and development expenditure (\% of GDP). 2020. Disponível em: https://data.worldbank.org/indicator/GB.XPD.RSDV.GD.ZS?view=chart. Acesso em: 29 ago. 2020.

TRZESNIAK, Piotr. A estrutura editorial de um periódico científico. Associação Brasileira de Editores Científicos de Psicologia, São Paulo, p.87-102, 2009. DOI:

http://dx.doi.org/10.13140/RG.2.1.2810.6965. Acesso em: 14 set. 2020.

\section{${ }^{1}$ Dyanara Lays Rohte Sbruzzi (Brasília, Distrito Federal, Brasil)}

Pós-graduanda em controladoria e contabilidade. Assistente administrativa da Revista Brasileira de Educação Médica.

Contribuição de autoria: Administração do Projeto, Conceituação, Escrita, Revisão e Edição, Investigação, Metodologia, Validação e Visualização.

Lattes: $\underline{\text { http://lattes.cnpq.br/7839777465385968 }}$

E-mail: dyanaralays@gmail.com

Avaliador(a) responsável:

Germana Fernandes Barata

\section{Como citar este artigo:}

SBRUZZI, Dyanara Lays Rohte. Conceitos de administração de empresas na gestão de periódicos científicos. In: ABEC Meeting Live, 2020. Anais... São Paulo: Associação Brasileira de Editores Científicos, 2020. DOI: http://dx.doi.org/10.21452/abecmeeting2020.02 